\title{
Technology Selection in the Presence of Dual-Role Factors
}

\section{Reza Farzipoor Saen}

Department of International Business and Asian Studies, Nathan campus, Nathan, Griffith University, QLD 4111, Australia

Tel: 0061 (07) 37357410

Email: farzipour@yahoo.com

\begin{abstract}
Technologies have varied strengths and weaknesses which require careful assessment by the purchasers. One of the uses of Data Envelopment Analysis (DEA) is technology selection. The traditional models of DEA do not consider dual-role factors. The objective of this paper is to use a model for selecting the best technologies in the presence of dual-role factors. The model determines whether in a technology the factors are behaving predominantly like inputs, hence the technology would benefit from having less of the factors, like outputs where more of the factors are desirable, or where they are in equilibrium. A numerical example demonstrates the application of the method.
\end{abstract}

Keywords: Technology selection, Data envelopment analysis, Dual-role factors

\section{Introduction}

Today, manufacturing organizations need to implement advanced manufacturing technologies such as industrial robots, computer numerical control machines, flexible manufacturing systems, automated material handling systems to gain competitive advantage and to enhance their strategic capabilities. These technologies have varied strengths and weaknesses which require careful assessment by the purchasers. Technology selection models help decision maker choose between evolving technologies. The reason for a special focus on technology selection is due to the complexity of their evaluation which includes strategic and operational characteristics (Karsak, 2008).

One of the uses of Data Envelopment Analysis (DEA) is technology selection. DEA was developed by Charnes et al. (1978) (Charnes, Cooper, Rhodes (CCR) model) to serve as a mechanism to evaluate the relative efficiencies of a set of similar decision making units (DMUs). In the usual setting, DMUs, for example, bank branches, hospitals, research projects, are evaluated relative to one another using a specified set of input and output factors. Outputs are meant to capture what the DMU generates; inputs represent the resources or circumstances that have led to the creation of those outputs.

In some situations there is a strong argument for permitting certain factors to simultaneously play the role of both inputs and outputs. In technology selection context, personnel education can be considered as both an input and an output. Remembering that the simple definition of efficiency is the ratio of output to input, an output can be defined as anything whose increase will cause an increase in efficiency. Similarly, an input can be defined as anything whose decrease will cause an increase in efficiency. If the personnel 
education is considered as an output, then the increase in the personnel education without a proportional increase in the cost of technology will increase the efficiency. Likewise, if the personnel education is considered as an input, then any decrease in the personnel education without a proportional decrease in the outputs will increase efficiency. So, depending on how one looks at it, either increasing or decreasing the personnel education can increase efficiency.

Beasley $(1990,1995)$, in a study of the efficiency of university departments, treated research funding on both the input and output sides. However, as Cook et al. (2006) addressed, the model proposed by Beasley $(1990,1995)$ has two limitations. The first limitation is that in the absence of constraints (e.g., assurance region or cone ratio) on the multipliers, each DMU will be $100 \%$ efficient. The second limitation is that the dual-role factor is considered as a discretionary factor.

Cook et al. (2006) developed a new model that has not the abovementioned limitations. However, their development pertains to a single dual-role factor and does not consider multiple dual-role factors.

The objective of this paper is to use a model for selecting technologies in the presence of multiple dual-role factors. This paper depicts technology selection process through a DEA model, while allowing for the incorporation of multiple dual-role factors. The chief advantage of the model is that it does not demand exact weights from the decision maker and considers multiple factors which simultaneously play both input and output roles.

This paper proceeds as follows. In Section 2, literature review is presented. Section 3 discusses the method for technology selection. Numerical example and managerial implications are discussed in Sections 4 and 5, respectively. Finally, concluding remarks are illustrated in Section 6.

\section{Literature review}

Some mathematical programming approaches have been used for technology selection in the past. To select the best computer-integrated manufacturing technologies, Yurdakul (2004) proposed a combined model of the Analytic Hierarchy Process (AHP) and Goal Programming (GP) to consider multiple objectives and constraints simultaneously. Chan et al. (2005) presented a fuzzy GP approach to model the machine tool selection and operation allocation problem of Flexible Manufacturing Systems (FMSs). However, one of the GP problems arises from a specific technical requirement. After the decision-maker specify the goals for each selected criterion, they must decide on a preemptive priority order of these goals, i.e., determining in which order the goals will be attained. Frequently such a priori input might not produce an acceptable solution and the priority structure may be altered to resolve the problem once more. In this fashion, it may be possible to generate a solution iteratively that finally satisfies the decision-maker. Unfortunately, the number of potential priority reorderings may be very large. A technology selection problem with five factors has up to 120 priority reorderings. Going through such a laborious process would be costly and inefficient. 
Hsu et al. (2010) provided a systematic approach towards the technology selection, in which two phase procedures were proposed. The first stage utilized fuzzy Delphi method to obtain the critical factors of the regenerative technologies by interviewing the experts. In the second stage, fuzzy AHP was applied to find the importance degree of each criterion as the measurable indices of the regenerative technologies. They considered eight kinds of regenerative technologies which have already been widely used, and established a ranking model that provides decision makers to assessing the prior order of regenerative technologies. Shen et al. (2010) suggest a hybrid technology selection approach integrating the fuzzy Delphi method, the AHP, and the Patent Co-citation Approach (PCA) to be utilized for identifying key technology areas. The Organic Light Emitting Diode (OLED) technology in Taiwan was used to be an example to illustrate the proposed technology selection process. Lee and Hwang (2010) proposed to use AHP as a tool for prioritizing the strategically promising nuclear technologies for commercial export from Korea. Jaganathan et al. (2007) proposed an integrated fuzzy AHP based approach to facilitate the selection and evaluation of new manufacturing technologies in the presence of intangible attributes and uncertainty. However, AHP has two main weaknesses. First subjectivity of AHP is a weakness. Second AHP could not include interrelationship within the criteria in the model.

Farzipoor Saen (2009b) proposed to use Artificial Neural Networks (ANNs) for technology selection in the presence of both continuous and categorical data. To indicate the relative importance of the ANN inputs to the result of the network, a methodology for sensitivity analysis was presented.

To assist managers in the correct justification and adoption of new manufacturing system attributes to ensure production and business success, a Quality Function Deployment (QFD)-based methodology was devised by Chuang et al. (2009). The proposed QFD-based methodology, simultaneously considers all the different criteria including competitive market requirements, as well as competitive business and operational strategies and manufacturing attributes in determining the most suitable production technology.

Dias-Neto and Travassos (2010) described a strategy to select model-based testing approaches for software projects called Porantim. Porantim is based on a body of knowledge describing model-based testing approaches and their characterization attributes (identified by secondary and primary experimental studies), and a process to guide by adequacy and impact criteria regarding the use of this sort of software technology that can be used by software engineers to select model-based testing approaches for software projects.

To select the best technologies in the existence of both cardinal and ordinal data, Farzipoor Saen (2006) proposed an innovative approach, which is based on Imprecise Data Envelopment Analysis (IDEA). Talluri et al. (2000) proposed a framework, which is based on the combined application of DEA and nonparametric statistical procedures, for the selection of FMSs. The strengths of this methodology are that it incorporates variability measures in the performance of alternative systems, provides decisionmaker with effective alternative choices by identifying homogeneous groups of systems, and presents 
graphic aids for better interpretation of results. Seiford and Zhu (2003) extended the context-dependent DEA by incorporating value judgment into the attractiveness and progress measures. The method was applied to measuring the attractiveness of 32 computer printers. They showed that the attractive measure helps (i) customers to select the best option, and (ii) printer manufacturers to identify the potential competitors. To select the best advanced manufacturing technologies, Karsak and Ahiska (2005) introduced a multi-criteria decision methodology that can integrate multiple outputs such as various technical characteristics and qualitative factors with a single input such as cost. Their model is derived from the cross-efficiency analysis, which is one of the branches of DEA model. Talluri and Yoon (2000) introduced advanced manufacturing technology selection process. They proposed a combination of a cone-ratio DEA model and a new methodological extension in DEA, while allowing for the incorporation of preferences of decision-makers. Karsak (2008) presented a decision methodology that enables the consideration of both exact and imprecise assessments in technology evaluation. The proposed framework considers the imprecise nature of some of the inputs and outputs by enabling both ordinal and fuzzy data to be used in the evaluation process. To select the best technologies in the presence of cardinal data, ordinal data, nondiscretionary factors, and weight restrictions, Farzipoor Saen (2009a) proposed a pair of assurance region-nondiscretionary factors-imprecise data envelopment analysis (AR-NF-IDEA) models.

However, all of the abovementioned references do not consider dual-role factors. A technique that can deal with dual-role factors is needed to better model such situation.

\section{Proposed method for technology selection}

DEA proposed by Charnes et al. (1978) (CCR model) and developed by Banker et al. (1984) (BCC model) is an approach for evaluating the efficiencies of DMUs. The CCR model measures the efficiency of $\mathrm{DMU}_{o}$ relative to a set of peer DMUs. CCR model is as below.

Consider a situation where members $k$ of a set of $K$ DMUs (technologies) are to be evaluated in terms of $R$ outputs $Y_{k}=\left(y_{r k}\right)_{r=1}^{R}$ and $I$ inputs $X_{k}=\left(x_{i k}\right)_{i=1}^{I}$.

$$
\begin{aligned}
& \max \frac{\sum_{r=1}^{R} \mu_{r} y_{r o}}{\sum_{i=1}^{I} v_{i} x_{i o}}, \\
& \frac{\sum_{r=1}^{R} \mu_{r} y_{r j}}{\sum_{i=1}^{I} v_{i} x_{i j}} \leq 1, \quad k=1, \ldots, K, \\
& \mu_{r}, v_{i} \geq 0 \quad \forall r \quad \text { and } \quad i
\end{aligned}
$$

where $\mu_{r}$ is the weight given to output $r$ and $v_{i}$ is the weight given to input $i$. DMU $U_{o}$ is the DMU under consideration. $\mathrm{DMU}_{o}$ consumes $x_{i o}(i=1, \ldots, I)$, the amount of input $i$, to produce $y_{r o}(r=1, \ldots, R)$, the amount of output $r$. DMU $\mathrm{DM}_{o}$ is said to be efficient if no other DMU or combination of DMUs can produce 
more than $\mathrm{DMU}_{o}$ on at least one output without producing less in some other output or requiring more of at least one input.

In addition, assume that a particular factor is held by each DMU in the amount $w_{k}$, and serves as both an input and output factor. The proposed model for considering single dual-role factor is as follows (Cook et al. 2006).

$$
\max \frac{\left(\sum_{r=1}^{R} \mu_{r} y_{r o}+\gamma w_{o}-\beta w_{o}\right)}{\sum_{i=1}^{I} v_{i} x_{i o}},
$$

st

$$
\begin{aligned}
& \sum_{r=1}^{R} \mu_{r} y_{r k}+\gamma w_{k}-\beta w_{k}-\sum_{i=1}^{I} v_{i} x_{i k} \leq 0, \quad k=1, \ldots, K \\
& \mu_{r}, v_{i}, \gamma, \beta \geq 0 .
\end{aligned}
$$

The linear programming form of Model (2) is as follows:

$$
z_{o}^{*}=\max \sum_{r=1}^{R} \mu_{r} y_{r o}+\gamma w_{o}-\beta w_{o},
$$

st

$$
\begin{aligned}
& \sum_{i=1}^{I} v_{i} x_{i o}=1, \\
& \sum_{r=1}^{R} \mu_{r} y_{r k}+\gamma w_{k}-\beta w_{k}-\sum_{i=1}^{I} v_{i} x_{i k} \leq 0, \quad k=1, \ldots, K \\
& \mu_{r}, v_{i}, \gamma, \beta \geq 0 .
\end{aligned}
$$

Model (3) could be extended in order to include multiple dual-role factors. Assume that some factors are held by each DMU in the amount $w_{f k}(f=1, \ldots, F)$, and serve as both an input and output factors. The proposed model for considering multiple dual-role factors is as follows (Farzipoor Saen, 2010):

$$
\max \frac{\left(\sum_{r=1}^{R} \mu_{r} y_{r o}+\sum_{f=1}^{F} \gamma_{f} w_{f o}-\sum_{f=1}^{F} \beta_{f} w_{f o}\right)}{\sum_{i=1}^{I} v_{i} x_{i o}},
$$

st

$$
\begin{aligned}
& \sum_{r=1}^{R} \mu_{r} y_{r k}+\sum_{f=1}^{F} \gamma_{f} w_{f k}-\sum_{f=1}^{F} \beta_{f} w_{f k}-\sum_{i=1}^{I} v_{i} x_{i k} \leq 0, \quad k=1, \ldots, K \\
& \mu_{r}, v_{i}, \gamma_{f}, \beta_{f} \geq 0 .
\end{aligned}
$$


The linear programming form of Model (4) is as follows:

$e_{o}^{*}=\max \sum_{r=1}^{R} \mu_{r} y_{r o}+\sum_{f=1}^{F} \gamma_{f} w_{f o}-\sum_{f=1}^{F} \beta_{f} w_{f o}$,

st

$$
\begin{aligned}
& \sum_{i=1}^{I} v_{i} x_{i o}=1, \\
& \sum_{r=1}^{R} \mu_{r} y_{r k}+\sum_{f=1}^{F} \gamma_{f} w_{f k}-\sum_{f=1}^{F} \beta_{f} w_{f k}-\sum_{i=1}^{I} v_{i} x_{i k} \leq 0, \quad k=1, \ldots, K \\
& \mu_{r}, v_{i}, \gamma_{f}, \beta_{f} \geq 0 .
\end{aligned}
$$

One of three possibilities exists in regard to the sign of $\hat{\gamma}_{f}-\hat{\beta}_{f}$, where $\hat{\gamma}_{f}, \hat{\beta}_{f}$ are the optimal values from Model (5); $\hat{\gamma}_{f}-\hat{\beta}_{f}>0$, =0, or $<0$.

Dual problem of Model (5) is as below.

$$
\begin{array}{llr}
\min & \theta_{o} & \\
\text { st } & & \\
& x_{i o} \theta_{o}-\sum_{k=1}^{K} x_{i k} \lambda_{k} \geq \mathbf{0} & i=1, \ldots, I \\
& \sum_{k=1}^{K} y_{r k} \lambda_{k} \geq y_{r o} & r=1, \ldots, R \\
& \sum_{k=1}^{K} w_{f k} \lambda_{k}=w_{f o} & f=1, \ldots, F \\
\lambda_{k} \geq 0 \quad \text { unrestricted in sign } &
\end{array}
$$

where $\theta_{o}$ and $\lambda_{k}$ are the dual variables. $\theta_{o}$ is radial input shrinkage factor (eventually to become efficiency measure) and $\lambda=\left\{\lambda_{k}\right\}$ is vector of DMU loadings, determining "best practice” for the DMU being evaluated. From the duality theory in linear programming, for an inefficient $\mathrm{DMU}_{o}, \lambda_{k}^{*}>0$ in the optimal dual solution implies that $\mathrm{DMU}_{k}$ is a unit of the peer group. A peer group of an inefficient $\mathrm{DMU}_{o}$ is defined as the set of DMUs that reach the efficiency score of 1 using the same set of weights that result in the efficiency score of $\mathrm{DMU}_{o}$. It is the existence of this collection of DMUs that forces the $\mathrm{DMU}_{o}$ to be inefficient. The peer groups serve as a benchmark to use in seeking improvements for inefficient technologies.

It is useful to comment here on an interesting relationship that exists between the constant returns to scale (CRS) model (Model (5)) and the standard (no dual-role factors present) variable returns to scale 
(VRS) model of Banker et al. (1984). Specifically, the VRS model with outputs $Y$ and inputs $X$ is given by:

$$
\max \left(\sum_{r=1}^{R} \mu_{r} y_{r o}-\mu_{o}\right) / \sum_{i=1}^{I} v_{i} x_{i o},
$$

st

$$
\begin{aligned}
& \sum_{r=1}^{R} \mu_{r} y_{r k}-\mu_{o}-\sum_{i=1}^{I} v_{i} x_{i k} \leq 0 \quad k=1, \ldots K, \\
& \mu_{r}, v_{i} \geq 0, \quad \mu_{o} \text { unrestricted in sign. }
\end{aligned}
$$

In the CRS model, $\mu_{o}$ is set to zero, and the supporting hyperplane to any facet of the frontier passes through the origin. Otherwise, $\mu_{o}$ is a form of "Y-intercept" to use an analogy with regression techniques. It is well known that the sign of $\mu_{o}$ identifies the "returns to scale" status of the $\mathrm{DMU}_{o}$. It is useful therefore to examine the three cases in regard to this sign, which will allow us to make important interpretations pertaining to the sign of the variables $\hat{\gamma}_{f}-\hat{\beta}_{f}$ (Cook et al., 2006).

Case 1: If $\mu_{o}>0$ in Model (7), then the $\mathrm{DMU}_{o}$ is said to be experiencing decreasing returns to scale (Banker et al. 1984). Thus, the marginal return, in terms of output, is less than the amounts of input required to produce that output. In "returns to scale" terminology, this DMU is not operating at the most productive scale size (MPSS), and would benefit from a reduction in size. A somewhat similar interpretation can be made in model (5) when $\hat{\gamma}_{f}-\hat{\beta}_{f}<0$. Using "personnel education" as the illustrative example, one might argue that $\mathrm{DMU}_{o}$ would experience an improvement in efficiency with fewer "personnel education". That is, in this particular technology, these factors are at a level where diminishing returns have set in, hence less of these factors would improve its performance ratio. One can say that in this case, the dual-role factors are "behaving like inputs".

Case 2: If $\mu_{o}<0$, then $\mathrm{DMU}_{o}$ is experiencing increasing returns to scale, and again it is not at the MPSS. This case is analogous to $\hat{\gamma}_{f}-\hat{\beta}_{f}>0$ in Model (5), meaning that this technology's efficiency would benefit from increased "personnel education". Specifically, these factors are at a level where they are "behaving like outputs", hence more of these factors are better, and would lead to an increase in efficiency.

Case 3: If $\mu_{o}=0$, then $\mathrm{DMU}_{o}$ is experiencing constant returns to scale, and the VRS Model (7) reduces to the standard CRS model of Charnes et al. (1978). The $\mathrm{DMU}_{o}$ would then be operating at the MPSS. In a technology selection setting, the analogous situation would be to have $\hat{\gamma}_{f}-\hat{\beta}_{f}=0$, meaning that the "personnel education" is at an equilibrium or optimal level. 
There are several previous works addressing the problem of including dual-role factors in DEA (e.g. Cook et al., 2006; Liang et al., 2006; Farzipoor Saen, 2010).

To the best of author's knowledge, there is not any reference that discusses technology selection in the presence of multiple dual-role factors. The approach presented in this paper has some distinctive features.

- The model does not demand exact weights from the decision-maker.

- The model considers multiple dual-role factors for technology selection.

- Technology selection is a straightforward process carried out by the model.

In the next section, numerical examples are presented.

\section{Numerical example}

\subsection{Example 1;}

In this subsection section, the proposed methodology that may be applied to a wide range of technology selection problems is used for FMS selection, and is illustrated through a previously reported industrial FMS selection problem. For the illustration of the idea proposed in this paper, the data sets of Karsak (2008) have been slightly changed. The FMS selection problem addressed in Karsak (2008) involves the evaluation of relative efficiency of 15 FMS alternatives with respect to attributes including "lead time reduction" and "amount of personnel education hours by the FMS supplier (AH)", which are considered in some sense as outputs. The inputs utilized in this paper are "capital \& operating cost", "required floor space", and "AH" which are considered in some sense as input. AH constitutes both output and input. Note that these measures are not exhaustive by any means, but frequently used in FMS's performance evaluation. In an application of this methodology, decision-makers must carefully identify appropriate inputs and outputs to be used in the decision making process. Table 1 depicts the FMS attributes. 
Table 1. Related attributes for 15 FMS alternatives

\begin{tabular}{|c|c|c|c|c|}
\hline \multirow{2}{*}{$\begin{array}{c}\text { FMS } \\
\text { alternative } \\
(\text { DMU) }\end{array}$} & $\begin{array}{c}|c| \\
\text { Required floor space } \\
\left(\mathrm{m}^{2}\right) \\
x_{1 k}\end{array}$ & $\begin{array}{c}\text { Capital \& operating } \\
\text { cost } \\
\left(\begin{array}{c}\text { million } \$) \\
x_{2 k}\end{array}\right.\end{array}$ & $\begin{array}{c}\text { Dual-role } \\
\text { factor }\end{array}$ & Output \\
\hline 1 & 650 & 3.9 & $w_{1 k}$ & $\begin{array}{c}\text { Lead time } \\
\text { reduction (\%) } \\
y_{1 k}\end{array}$ \\
\hline 2 & 730 & 5.8 & 60 & 40 \\
\hline 3 & 680 & 3.7 & 100 & 18 \\
\hline 4 & 425 & 5.1 & 90 & 22 \\
\hline 5 & 510 & 6.3 & 115 & 65 \\
\hline 6 & 630 & 3.7 & 105 & 35 \\
\hline 7 & 550 & 5.7 & 135 & 20 \\
\hline 8 & 720 & 5.1 & 120 & 25 \\
\hline 9 & 475 & 6 & 80 & 13 \\
\hline 10 & 780 & 6.7 & 90 & 15 \\
\hline 11 & 490 & 4.2 & 85 & 41 \\
\hline 12 & 760 & 3.8 & 90 & 24 \\
\hline 13 & 850 & 6.3 & 65 & 38 \\
\hline 14 & 550 & 4.1 & 110 & 18 \\
\hline 15 & 530 & 5.5 & 125 & 55 \\
\hline
\end{tabular}

Applying Model (5), the efficiency scores of FMS alternatives (DMUs), and their inputs/outputs behavior have been presented in Table 2. As well, applying Model (6), peer groups of FMS alternatives have been presented in the last column of Table 2.

Table 2. The efficiency scores, input/output behavior and peer group for the 15 FMS alternatives

\begin{tabular}{|c|c|c|c|c|c|}
\hline $\begin{array}{c}\text { FMS } \\
\text { alternative } \\
\text { (DMU) }\end{array}$ & Efficiency score & $\hat{\gamma}_{1}$ & $\hat{\beta}_{1}$ & $\hat{\gamma}_{1}-\hat{\beta}_{1}$ & Peer group \\
\hline 1 & .873 & .005 & 0 & .005 & 4,15 \\
\hline 2 & .661 & .006 & 0 & .006 & $7,14,15$ \\
\hline 3 & .903 & .008 & 0 & .008 & 6,15 \\
\hline 4 & 1 & 0 & 0 & 0 & NA \\
\hline 5 & .936 & .008 & 0 & .008 & 7,15 \\
\hline 6 & 1 & .009 & 0 & .009 & NA \\
\hline 7 & 1 & .007 & 0 & .007 & NA \\
\hline 8 & .947 & .006 & 0 & .006 & 6,15 \\
\hline 9 & .686 & .009 & 0 & .009 & 7 \\
\hline 10 & .53 & .006 & 0 & .006 & 7,14 \\
\hline 11 & .939 & .005 & 0 & .005 & 4,15 \\
\hline 12 & .898 & .008 & 0 & .008 & 6,15 \\
\hline 13 & .538 & .003 & 0 & .003 & 4,15 \\
\hline 14 & 1 & .009 & 0 & .009 & NA \\
\hline 15 & 1 & .004 & 0 & .004 & NA \\
\hline
\end{tabular}

Model (5) identified FMS alternatives 4, 6, 7, 14, and 15 to be efficient with a relative efficiency score of 1 . The remaining FMS alternatives with relative efficiency scores of less than 1 are considered to be inefficient. Therefore, decision maker can choose one or more of these efficient FMS alternatives. 
To rank the efficient FMS alternatives, the approach developed by Torgersen et al. (1996) is used. Their approach for ranking of efficient DMUs is based on peer groups. They concluded that a DMU was highly ranked if it was chosen as a reference by many other inefficient DMUs. The ranking result has been indicated in Table 3. As Table 3 shows, FMS alternative 15 is the most efficient technology.

Table 3. The ranking results of efficient FMS alternatives

\begin{tabular}{|c|c|}
\hline Efficient FMS alternatives & Rank \\
\hline 15 & 1 \\
\hline 7 & 2 \\
\hline 4 and 6 & 3 \\
\hline 14 & 4 \\
\hline
\end{tabular}

All FMS alternatives, except for FMS alternative 4, are those that $\mathrm{AH}$ is behaving like an output, where more of such factor would improve the efficiencies of related FMS alternatives. Therefore, these FMS alternatives are said to be experiencing increasing returns to scale.

The FMS alternative 4 is the alternative that $\mathrm{AH}$ is in equilibrium. Therefore, this FMS alternative is said to be experiencing constant returns to scale.

Also, the last column of Table 2 provides peer groups for inefficient FMS alternatives. Note that, each DEA model seeks to determine which of the $k$ DMUs define an envelopment surface that represents best practice, referred to as the empirical production function or the efficient frontier. DMUs that lie on the surface are deemed efficient in DEA while those DMUs that do not, are termed inefficient. DEA provides a comprehensive analysis of relative efficiencies for multiple input-multiple output situations by evaluating each DMU and measuring its performance relative to an envelopment surface composed of other DMUs. Those DMUs are the peer group for the inefficient DMUs known as the efficient reference set. As the inefficient DMUs are projected onto the envelopment surface, the efficient DMUs closest to the projection and whose linear combination comprises this virtual DMU form the peer group for that particular DMU. The targets defined by the efficient projections give an indication of how this DMU can improve to be efficient. The peer groups serve as a benchmark to use in seeking improvements for inefficient FMS alternatives. Inefficient FMS alternative suppliers can use these results from a marketing perspective.

\subsection{Example 2;}

We use data for 12 robots used in Amin (2009) which is replicated here in Table 4. This Table contains the normalized data for two engineering attributes (handling coefficient and load capacity) which are considered as the outputs and a single input (cost). For the illustration of the idea proposed in this 
paper, the data sets of Amin (2009) have been slightly changed. The "amount of personnel education hours by the robot supplier (RH)", is considered as dual-role factor, as well.

Table 4. Related attributes for 12 robot alternatives

\begin{tabular}{|c|c|c|c|c|}
\hline \multirow{2}{*}{$\begin{array}{c}\text { Robot } \\
\text { alternative } \\
\text { (DMU) }\end{array}$} & Input & Dual-role factor & \multicolumn{2}{|c|}{ Outputs } \\
\cline { 2 - 5 } & $x_{1 k}$ & $\begin{array}{c}\text { RH } \\
w_{1 k}\end{array}$ & $\begin{array}{c}\text { Handling } \\
\text { coefficient } \\
y_{1 k}\end{array}$ & $\begin{array}{c}\text { load capacity } \\
y_{2 k}\end{array}$ \\
\hline 1 & 1 & 0.22 & 1 & 0.85 \\
\hline 2 & 0.75 & 0.321 & 0.938 & 0.45 \\
\hline 3 & 0.562 & 0.256 & 0.879 & 0.18 \\
\hline 4 & 0.281 & 1 & 0.411 & 0.1 \\
\hline 5 & 0.469 & 0.897 & 0.822 & 0.2 \\
\hline 6 & 0.781 & 0.664 & 0.667 & 0.6 \\
\hline 7 & 0.875 & 0.246 & 0.884 & 0.9 \\
\hline 8 & 0.562 & 0.457 & 0.636 & 0.1 \\
\hline 9 & 0.562 & 0.356 & 0.656 & 0.25 \\
\hline 10 & 0.875 & 0.479 & 0.751 & 1 \\
\hline 11 & 0.687 & 0.258 & 0.884 & 1 \\
\hline 12 & 0.437 & 0.555 & 0.636 & 0.7 \\
\hline
\end{tabular}

Applying Model (5), the efficiency scores of robot alternatives (DMUs), and their inputs/outputs behavior have been presented in Table 5 .

Table 5. The efficiency scores and input/output behavior for the 12 robot alternatives

\begin{tabular}{|c|c|c|c|c|}
\hline $\begin{array}{c}\text { Robot } \\
\text { alternative } \\
\text { (DMU) }\end{array}$ & Efficiency score & $\hat{\gamma}_{1}$ & $\hat{\beta}_{1}$ & $\hat{\gamma}_{1}-\hat{\beta}_{1}$ \\
\hline 1 & 1 & 0 & 3.69 & -3.69 \\
\hline 2 & .84 & 0 & .2 & -0.2 \\
\hline 3 & 1 & 0 & .15 & -0.15 \\
\hline 4 & 1 & 1 & 0 & 1 \\
\hline 5 & 1 & .18 & 0 & 0.18 \\
\hline 6 & .57 & .11 & 0 & 0.11 \\
\hline 7 & .82 & 0 & 4.22 & -4.22 \\
\hline 8 & .68 & 0 & .15 & -0.15 \\
\hline 9 & .74 & 0 & .16 & -0.16 \\
\hline 10 & .76 & 0 & .13 & -0.13 \\
\hline 11 & 1 & 0 & .17 & -0.17 \\
\hline 12 & 1 & 0 & 0 & 0 \\
\hline
\end{tabular}

Model (5) identified robot alternatives $1,3,4,5,11$, and 12 to be efficient with a relative efficiency score of 1 . Therefore, decision maker can choose one or more of these efficient robots. Robots 4, 5, and 6 are those that RH is behaving like an output, where more of such factor would improve the efficiencies of related robots. Robots 1, 2, 3, 7, 8, 9, 10, and 11 are those that $\mathrm{RH}$ is behaving like an input, where less of such factor would improve the efficiencies of related robots. The robot 12 is the alternative that $\mathrm{RH}$ is in equilibrium. 


\section{Managerial implications}

The methodology can be applied from both a buyer's and technology supplier's perspective. The buyer can use it as a justification tool for identifying "good practice" technologies in terms of technical specifications and capital cost. With the review of inefficient technologies, it may be possible for the buyer to negotiate changes in the cost-performance of these inefficient technologies with their technology suppliers that will make the technologies competitive with efficient technologies. However, the technology suppliers may not be willing to reduce the price of a technology. The technology suppliers can also use results from DEA in market competitive analysis. They may utilize the peer groups to identify competitors and niche players in a crowded market. The technology supplier who achieved an efficiency score of 1 , when compared with other technologies, can use these results to promoting its product. On the other hand, if a particular technology is poorly performing, then the technology supplier of this technology can use the analysis for benchmarking purposes.

A complete assessment of the approach presented in this study would require stating the following critical points. First, the approach improves the quality of technology selection, but by no means it is aimed to fully replace management judgment. Although the framework enables one to systematically incorporate the dual-role factors into the decision process, subjective judgment is still required to select the inputs and outputs and possibly limit their number as well as to interpret the results of the analysis. Second, for a decision-maker who is not familiar with mathematical programming, DEA may appear as a "black box". A user-friendly interface could be helpful for further appreciation of the approach.

Despite the above-mentioned critiques, the merits of the decision making approach that considers dual-role factors in the technology selection process are notable, and facilitate its use as a viable decision making tool by organizations considering technology investments.

\section{Concluding remarks}

Modern technology plays a key role in the ability of manufacturing companies to compete as world class manufacturers. Managers need to make complex decisions regarding applicable technologies in order to gain strategic competitive edge.

In this paper DEA has been proposed as a potential tool for selecting technologies in the presence of multiple dual-role factors. The main advantage of DEA is that it enables the decision maker to handle multiple criteria without relying on subjective judgments involved in the evaluation process. The analyses determine whether in a technology the factors are behaving predominantly like inputs, hence the technology would benefit from having less of the factors, like outputs where more of the factors are desirable, or where they are in equilibrium. Meanwhile, these ideas were connected to those involving increasing, decreasing and constant returns to scale. Also, this paper proposed a systematic analysis to provide peer groups for inefficient technology suppliers. In addition, this paper describes how the 
proposed approach has been applied to select FMS technologies. The FMS selection revealed that the proposed framework can satisfy the real requirements of an individual company as well as ensure a competitive advantage.

The problem considered in this study is at initial stage of investigation and further researches can be done based on the results of this paper. Some of them are as below:

- Similar research can be repeated for dealing with ordinal data, fuzzy data, and bounded data in the conditions that dual-role factors exist.

- In this study, the model has been applied to a problem related to FMS selection. However, the same models could be applied, with minor modifications, to other problems related to selection of robots, computer integrated manufacturing systems, computer numerical control systems and many other technology selection decision cases.

- The numerical example has shown that DEA can be seen as a normative model for helping a buyer to evaluate technologies. It does not require an a priori weighting scheme to combine various dimensions of technology performance into an overall rating for each technology. However, the DEA model can be restructured to allow for weight restrictions if necessary.

\section{Acknowledgements}

The author wishes to thank an anonymous referee for the valuable suggestions and comments.

\section{References}

Amin G. R. (2009) Optimal solution of technology selection model: a computational efficient form, The International Journal of Advanced Manufacturing Technology, Vol. 43, No. ***, pp. 1046-1050.

Banker R. D., Charnes A., Cooper W. W. (1984) Some Methods for Estimating Technical and Scale Inefficiencies in Data Envelopment Analysis, Management Science, Vol. 30, No. 9, pp. 1078-1092.

Beasley J. (1990) Comparing University Departments, Omega, Vol. 8, No. 2, pp. 171-183.

Beasley J. (1995) Determining Teaching and Research Efficiencies, Journal of the Operational Research Society, Vol. 46, No. 4, pp. 441-452.

Chan F. T. S., Swarnkar R., Tiwari M. K. (2005) Fuzzy Goal-Programming Model with an Artificial Immune System (AIS) Approach for a Machine Tool Selection and Operation Allocation Problem in a Flexible Manufacturing System, International Journal of Production Research, Vol. 43, No. 19, pp. 41474163. 
Charnes A., Cooper W. W., Rhodes E. (1978) Measuring the Efficiency of Decision Making Units, European Journal of Operational Research, Vol. 2, No. 6, pp. 429-444.

Chuang M., Yang Y. S., Lin C. T. (2009) Production technology selection: Deploying market requirements, competitive and operational strategies, and manufacturing attributes, International Journal of Computer Integrated Manufacturing, Vol. 22, No. 4, pp. 345-355.

Cook W. D., Green R. H., Zhu J. (2006) Dual-Role Factors in Data Envelopment Analysis, IIE Transactions, Vol. 38, No. 2, pp. 105-115.

Dias-Neto A. C., Travassos G. H. (2010) Model-based testing approaches selection for software projects, Information and Software Technology, Vol. 51, No. ****, pp. 1487-1504.

Farzipoor Saen R. (2006) A decision model for technology selection in the existence of both cardinal and ordinal data, Applied Mathematics and Computation, Vol. 181, No. 2, pp. 1600-1608.

Farzipoor Saen R. (2009a) Technology Selection in the Presence of Imprecise Data, Weight Restrictions, and Nondiscretionary Factors, The International Journal of Advanced Manufacturing Technology, Vol. 41, No. 7-8, pp. 827-838.

Farzipoor Saen R. (2009b) The Use of Artificial Neural Networks for Technology Selection in the Presence of both Continuous and Categorical Data, World Applied Sciences Journal, Vol. 6, No. 9, pp. 1177-1189.

Farzipoor Saen R. (2010) A New Model for Selecting Third-Party Reverse Logistics Providers in the Presence of Multiple Dual-Role Factors, The International Journal of Advanced Manufacturing Technology, Vol. 46, No. 1-4, pp. 405-410.

Hsu Y. L., Lee C. H., Kreng V. B. (2010) The application of fuzzy Delphi method and fuzzy AHP in lubricant regenerative technology selection, Expert Systems with Applications, Vol. 37, No. ***, pp. 419425.

Jaganathan S., Erinjeri J. J., Ker J. (2007) Fuzzy Analytic Hierarchy Process Based Group Decision Support System to Select and Evaluate New Manufacturing Technologies, International Journal of Advanced Manufacturing Technology, Vol. 32, No. 11-12, pp. 1253-1262. 
Karsak E. E. (2008) Using Data Envelopment Analysis for Evaluating Flexible Manufacturing Systems in the presence of Imprecise Data, International Journal of Advanced Manufacturing Technology, Vol. 35, No. 9-10, pp. 867-874.

Karsak E. E., Ahiska S. S. (2005) Practical Common Weight Multi-Criteria Decision-Making Approach with an Improved Discriminating Power for Technology Selection, International Journal of Production Research, Vol. 43, No. 8, pp. 1537-1554.

Lee D. J., Hwang J. (2010) Decision support for selecting exportable nuclear technology using the analytic hierarchy process: A Korean case, Energy Policy, Vol. 38, No. ****, pp. 161-167.

Liang L., Yang F., Cook W. D., Zhu J. (2006) DEA Models for Supply Chain Efficiency Evaluation, Annals of Operations Research, Vol. 145, No. 1, pp. 35-49.

Seiford L. M., Zhu J. (2003) Context-Dependent Data Envelopment Analysis-Measuring Attractiveness and Progress, Omega, Vol. 31, No. 5, pp. 397-408.

Shen Y. C., Chang S. H., Lin G. T. R., Yu H. C. (2010) A hybrid selection model for emerging technology, Technological Forecasting \& Social Change, Vol. 77, No. ****, pp. 151-166.

Talluri S., Whiteside M. M., Seipel S. J. (2000) A Nonparametric Stochastic Procedure for FMS Evaluation, European Journal of Operational Research, Vol. 124, No. 3, pp. 529-538.

Talluri S., Yoon K.P. (2000) A cone-ratio DEA Approach for AMT Justification, International Journal of Production Economics, Vol. 66, No. 2, pp. 119-129.

Torgersen A. M., Forsund F. R. and Kittelsen S. A. C. (1996) Slack-Adjusted Efficiency Measures and Ranking of Efficient Unit, Journal of Productivity Analysis, Vol. 7, No. 4, pp. 379-398.

Yurdakul M. (2004) Selection of Computer-Integrated Manufacturing Technologies Using a Combined Analytic Hierarchy Process and Goal Programming Model, Robotics and Computer-Integrated Manufacturing, Vol. 20, No. 4, pp. 329-340. 